\title{
Knowledge, Attitude and Practice about Breast Cancer among Women in Saudi Arabia
}

Amira S. Ahmed', Rehab M. El-Gharabawy², Haneen O. AL-Suhaibany ${ }^{3}$

1 Hormone Department, National Research Centre, Egypt.

2 Pharmacology \& Toxicology Department, Faculty of Pharmacy, Tanta University, Egypt.

3 Faculty of Pharmacy, Qassim University, Saudi Arabia.

Contact information:

Amira S. Ahmed.

Address: Hormone Department, National Research Centre, Egypt

झ dr.amira2007@yahoo.com
Results: Out of 764 participants, only 159 (20.81\%), 151(19.76\%) and 99 (12.96\%) practiced BSE, CBE and mammography respectively. The knowledge and practice of CBE and mammography were significantly decreased with increasing the age. The married women showed significantly more practice of $B S E, C B E$ and mammography than single ones (OR: 1.6 (1.1-2.3), $\mathrm{P}<0.014$; OR: 3.7 (2.4-5.8), $\mathrm{P}<0.00001$ and OR: 4.2 (2.4-7.2), $\mathrm{P}<0.00001$ respectively).

Conclusion: The study points to the insufficient knowledge of female about breast cancer and identified the negative influence of low knowledge on the attitude and practice of BSE, CBE and mammography. Therefore, more efforts are needed to develop a positive attitude toward BSE, CBE and mammography screening practice in the country. 


\section{Introduction}

Breast cancer $(\mathrm{BC})$ is considered to be one of the most common malignancies and the second leading cause of cancer deaths in women after lung cancer, worldwide. The breast cancer forms about $23 \%$ of all female cancers [1, 2, 3]. The breast cancer is ranked as the most common cancer in females according to the Saudi Cancer Registry (SCR). It is accounted for $25 \%$ of all newly diagnosed female cancers in KSA [4].

Early breast cancer stage is usually asymptomatic. As the tumor grows, main symptoms are breast lump or lump in the armpit that is hard, has uneven edges, and usually does not hurt. Also, change in the size, shape, or feel of the breast or nipple (redness, dimpling, puckering that looks like the skin of an orange, fluid from the nipple may be bloody, clear to yellow, green, or look like pus). On the other hand, the symptoms of advanced breast cancer may exhibit the following symptoms; bone pain, breast pain or discomfort, skin ulcers, swelling of the lymph nodes in the armpit and weight loss $[5,6]$.

Numerous risk factors are associated with breast cancer. One major risk factor is increasing age. The most important ones include both a personal and a family history of breast cancer and some specific genetic mutations and hyperplasia. Other risk factors are an early menarche and late menopause, obesity after menopause, use of iatrogenic hormones (both oral contraceptives and postmenopausal hormone therapy have been implicated), nulliparity or having the first child after the age of thirty $[7,8]$.

Early detection of breast cancer can be achieved by performed breast self-examination (BSE), clinical breast examination (CBE) and mammography [9]. It is important to adequately motivate women to regularly carry out BSE so as to curtail the increasing mortality rate from breast cancer [10]. The practice of BSE may have great value in terms of awareness and motivating women to see a health care provider when they find a lump. Also, the earlier response to symptoms may reduce the cancer stage at diagnosis. In addition, BSE may be an effective primary tool in breast health education [11].

Therefore, the education of women about the warning signs, symptoms and strive for improvement of health behavior by making them aware are important steps to drag down high incidence and mortality rate from breast cancer. In this regard, different professions like medical professionals, media, academic teachers and leaders can play a vital role to educate people [12]. The main goal of the present work was to assess knowledge, attitude and practice about breast self-examination, clinical breast examination and mammography as early detection tools for breast cancer among females in Saudi Arabia, to compare the findings of the study with the related studies done in other places and to help in designing a proper health education scheme regarding breast cancer.

\section{Design of the Work}

A national adaptive cross-sectional survey [13, 14] was conducted on 764 Saudi Arabian women aged from twenty to above sixty years old in March, 2015. A standardized, confidential, Internet questionnaire (An electronic questionnaire was used for a large population of women in all regions of Saudi Arabia) was offered to randomly selected female members.

Inclusion criteria:

1) Age 20-70 year.

2) Only Saudi Arabian female involved in the study.

\section{Questionnaire Design}

The questionnaire was designed in English with later translated to Arabic and reviewed for consistency by the supervisor. The questionnaire included Socio-demographic characteristics of the participants and questions on awareness campaign in Saudi Arabia followed by twenty questions related to knowledge (Family history, risk factors, symptoms, prevalence and importance of early de- 
tection). Also, questionnaire included other items regarding to attitude toward and practice of BSE, CBE and mammograph.

\section{Data analysis}

The data were collected and tabulated. The recorded data were analyzed using computer based statistical package for social science (SPSS, V.22, IBM Corp., USA, 2013).

Simple descriptive statistics were used (frequency with percentage distribution for categorized variables). Chi-square cross tabulation was used to test the differences in proportions of categorical variable between two or more groups and assess/find correlation between the variables. Odds ratio (OR) together with $95 \%$ confidence intervals $(95 \% \mathrm{Cls}$ ) were used to measure the association between variables. The level of statistical significance was set at probability $\mathrm{P} \leq 0.05$.

\section{Results}

Seven hundred and sixty four questionnaires were received complete and considered for the analysis. Table 1 showed the socio-demographic characteristics of the participants. The majority of participants, four hundred fifteen (54.32\%), were between 20 to 30 years of age followed by $209(27.36 \%)$ who were between the age group of 31 to 40 years. Four hundred thirty nine (57.46\%) were married, $325(42.54 \%)$ were single. Majority of the participants, 496(64.92\%) had a university bachelor degree, $81(10.60 \%)$ had high school diploma, and 46(6.02\%) participants had higher educational qualifications (masters and PhD degrees).

Perception of breast cancer, knowledge of awareness campaigns in Saudi Arabia, family history of breast cancer and the importance of early detection in improvement of treatment were represented in Table 2. Several activities, events, and campaigns took place to promote better knowledge and encourage early detection throughout the country.
Table 1. Socio-demographic characteristics of participants $(n=764)$.

\begin{tabular}{|c|c|c|}
\hline Characteristics & $\mathbf{N}$ & $\%$ \\
\hline \multicolumn{3}{|l|}{ Age (years) } \\
\hline $20-30$ & 415 & 54.32 \\
\hline $31-40$ & 209 & 27.36 \\
\hline $41-50$ & 99 & 12.96 \\
\hline $51-60$ & 39 & 5.10 \\
\hline Above 60 & 2 & 0.26 \\
\hline \multicolumn{3}{|l|}{ Education } \\
\hline Average & 17 & 2.22 \\
\hline Secondary & 124 & 16.23 \\
\hline Diploma & 81 & 10.60 \\
\hline Bachelor & 496 & 64.92 \\
\hline High education & 46 & 6.02 \\
\hline \multicolumn{3}{|l|}{ Occupation } \\
\hline Don't work & 148 & 19.37 \\
\hline Students & 258 & 33.77 \\
\hline Part Time & 33 & 4.32 \\
\hline Full Time & 241 & 31.54 \\
\hline From Home & 55 & 7.20 \\
\hline Retired & 29 & 3.80 \\
\hline \multicolumn{3}{|l|}{ Marital Status } \\
\hline Single & 439 & 57.46 \\
\hline Married & 325 & 42.54 \\
\hline \multicolumn{3}{|l|}{ Area of Residence } \\
\hline Western Region & 41 & 5.37 \\
\hline Eastern Region & 22 & 2.88 \\
\hline Central Region & 666 & 87.17 \\
\hline Southern Region & 21 & 2.750 \\
\hline Northern Region & 14 & 1.83 \\
\hline Total & 764 & 100 \\
\hline \multicolumn{3}{|c|}{$\begin{array}{r}\text { Some results are expressed as percentages }(\%),(\mathrm{N}) \text { : } \\
\text { Number of participants }\end{array}$} \\
\hline
\end{tabular}


Table 2. Participants' perception about breast cancer, family history, awareness campaigns and importance of early detection in the treatment.

\begin{tabular}{|c|c|c|c|}
\hline Questions & \multicolumn{2}{|l|}{$\mathbf{N}$} & $\%$ \\
\hline \multirow{3}{*}{$\begin{array}{l}\text { Do you think that } \\
\text { breast cancer leads to } \\
\text { death? }\end{array}$} & Yes & 354 & 46.34 \\
\hline & No & 274 & 35.86 \\
\hline & I don't know & 136 & 17.80 \\
\hline \multirow{3}{*}{$\begin{array}{l}\text { Do you have any } \\
\text { family history of breast } \\
\text { cancer? }\end{array}$} & Yes & 137 & 17.93 \\
\hline & No & 585 & 76.57 \\
\hline & I don't know & 42 & 5.50 \\
\hline \multirow{3}{*}{$\begin{array}{l}\text { Are you aware } \\
\text { of breast cancer } \\
\text { campaigns and } \\
\text { activities? }\end{array}$} & Yes & 249 & 32.59 \\
\hline & No & 346 & 45.29 \\
\hline & I don't know & 169 & 22.12 \\
\hline \multirow{3}{*}{$\begin{array}{l}\text { Do you think that } \\
\text { the early detection } \\
\text { improves the treatment } \\
\text { of breast cancer? }\end{array}$} & Yes & 741 & 96.99 \\
\hline & No & 4 & 0.52 \\
\hline & I don't know & 19 & 2.49 \\
\hline Total & \multicolumn{2}{|l|}{764} & 100 \\
\hline
\end{tabular}

Table 3. Breast cancer risk factors, signs and symptoms identified by the participants.

\begin{tabular}{|l|c|c|}
\hline & N & $\%$ \\
\hline Risk factors & & \\
\hline Advanced age & 400 & 52.36 \\
\hline Family history with breast cancer & 493 & 64.53 \\
\hline Smoking & 528 & 69.11 \\
\hline Obesity & 333 & 43.59 \\
\hline Delivery of first child after the age of 30 & 187 & 24.48 \\
\hline Early menstruation & 85 & 11.13 \\
\hline Late menopause & 215 & 28.14 \\
\hline Short periods of breast feeding & 14 & 1.83 \\
\hline Use of contraceptive pills & 356 & 46.60 \\
\hline Signs and symptoms & & \\
\hline Bloody discharge from nipple & 579 & 75.79 \\
\hline Lump in breast & 707 & 92.54 \\
\hline Change in breast skin & 639 & 83.64 \\
\hline
\end{tabular}

Some results are expressed as percentages (\%),

(N): Number of participants
Two hundred forty nine (32.59\%), have recognized that. Three hundred fifty four (46.34\%), 137(17.93\%) and 741 (96.99\%) of participants have knowledge about the possibility of death by breast cancer, family history of breast cancer and knowledge of the improvement of breast cancer treatment by early detection respectively.

When asked about the risk factors of breast cancer. These factors were presented in Table 3. The most identified risk factor was smoking 528 (69.11\%) followed by family history 493 (64.53\%). While the least identified factor was short periods of breast feeding 14 (1.83\%). The majority of risk factors were identified by women 30 years of age or younger. While, women over 60 years only managed to identify 2 to 3 risk factors. On the other hand, when asked about signs and symptoms of breast cancer the most identified symptoms was lump in the breast707 (92.54\%) followed by change in breast skin 639 (83.64\%).

Results from the three main questions that assessed participants' knowledge on BSE and mammography practice were shown in Table 4. Six hundred fifty seven (85.99\%) admitted BSE usefulness in early detection of breast cancer. On the other hand, 666 (87.17\%) admitted CBE usefulness in early detection of breast cancer. Four hundred seventy six (62.30\%) admitted mammography usefulness in early detection; however, only 257 (33.64\%) identified the correct age for screening. In addition, 406 (53.14\%) of the participants recognized the correct screening frequency.

Figure 1 showed positive attitude toward Breast Self-Examination where 651(85.21\%) of participants recommend their family to do that examination.

When asked about reasons for prevention of getting medical advice, the highest percentage 244 (31.94\%) of chosen barrier was "worry about finding a lump" followed by 194 (25.39\%) "no time". While the last percentage twenty (2.62\%) was "going to a doctor or hospital will not help me", as demonstrated in Figure 2. 


\section{INTERNATIONAL ARCHIVES OF MEDICINE

Table 4. Knowledge about BSE, CBE and mammography practices.

\begin{tabular}{|l|c|c|}
\multicolumn{1}{|c|}{ Questions } & N & $\%$ \\
\hline \multicolumn{1}{|c|}{ BSE } \\
\hline How is your general knowledge about BSE? \\
\hline Excellent/Good & 81 & 10.60 \\
\hline Fair & 202 & 26.44 \\
\hline Poor & 316 & 41.36 \\
\hline I don't know & 165 & 21.60 \\
\hline
\end{tabular}

Do you think that BSE is very useful for early detection of breast cancer?

\begin{tabular}{|l|c|c|}
\hline Yes & 657 & 85.99 \\
\hline No & 107 & 14.01 \\
\hline Which of the following is appropriate time for BSE? \\
\hline Few days before menses & 51 & 6.68 \\
\hline Few days after menses & 287 & 37.57 \\
\hline During menses & 51 & 6.68 \\
\hline No specific time & 157 & 20.55 \\
\hline Don't know & 218 & 28.53 \\
\hline Total & 764 & 100 \\
\hline
\end{tabular}

If you feel a lump in breast, do you know the importance of $\mathrm{CBE}$ ?

\begin{tabular}{|l|c|c|}
\hline Yes & 666 & 87.17 \\
\hline No & 98 & 12.83 \\
\hline Total & 764 & 100 \\
\hline & & \\
\hline
\end{tabular}

How is your general knowledge about mammography?

\begin{tabular}{|l|c|c|}
\hline Excellent/Good & 99 & 12.96 \\
\hline Fair & 112 & 14.66 \\
\hline Poor & 163 & 21.34 \\
\hline I don't know & 390 & 51.05 \\
\hline
\end{tabular}

Do you think that mammography is very useful for early detection of breast cancer?

\begin{tabular}{|l|l|l|}
\hline Yes & 476 & 62.30 \\
\hline No & 288 & 37.69 \\
\hline
\end{tabular}

\begin{tabular}{|l|c|c|}
\hline \multicolumn{1}{|c|}{ Questions } & Nammography & $\%$ \\
\hline When should a woman start having mammograms? \\
\hline 15-20 years & 39 & 5.10 \\
\hline 21-30 years & 155 & 20.29 \\
\hline 30-40 years & 273 & 35.73 \\
\hline Over 40 years & 257 & 33.64 \\
\hline Over 50 years & 40 & 5.24 \\
\hline At what frequency should a woman have her & \\
\hline mammograms? & 406 & 53.14 \\
\hline Every year to two years & 79 & 10.34 \\
\hline Every five years & 149 & 19.50 \\
\hline When a doctor request it & 130 & 17.02 \\
\hline I don't know & 764 & 100 \\
\hline Total
\end{tabular}

Some results are expressed as percentages (\%), (N): Number of participants

Figure 1: Attitude toward Breast Self-Examination.

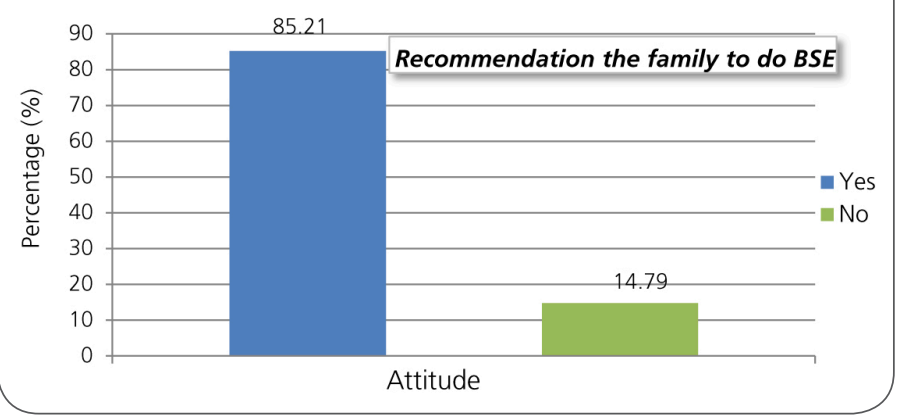

Figure 2: Attitude toward Clinical Breast Examination.

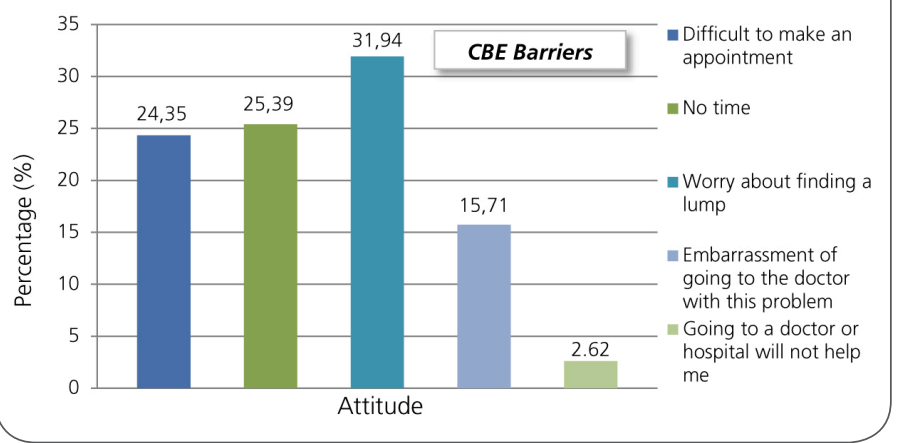


Figure 3: Attitude toward Mammography, Mammography barriers.

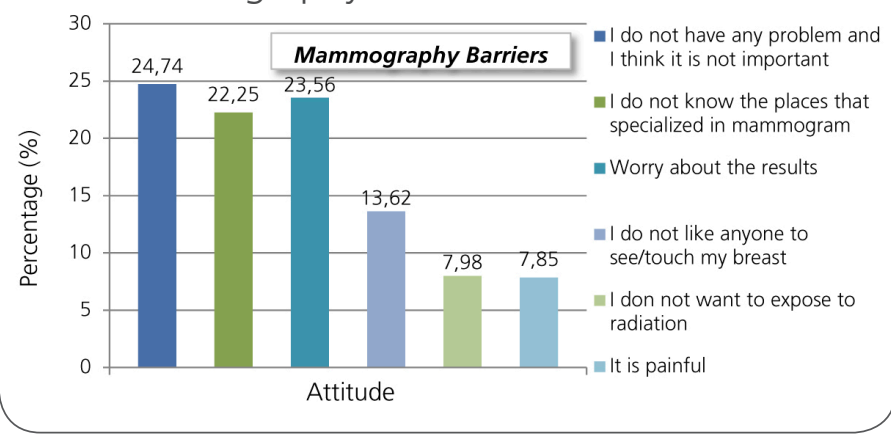

Figure 4: Attitude toward Mammography, feeling before the appointment.

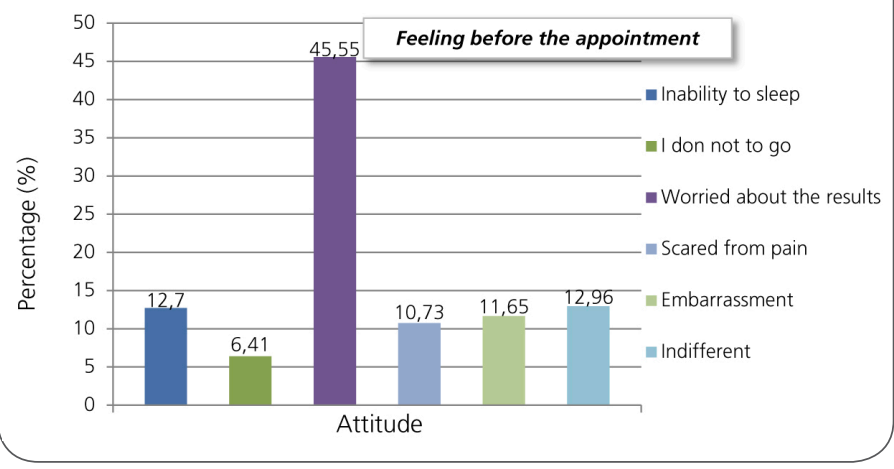

Figure 5: Practices of breast self-examination, clinical breast examination and mammogram.

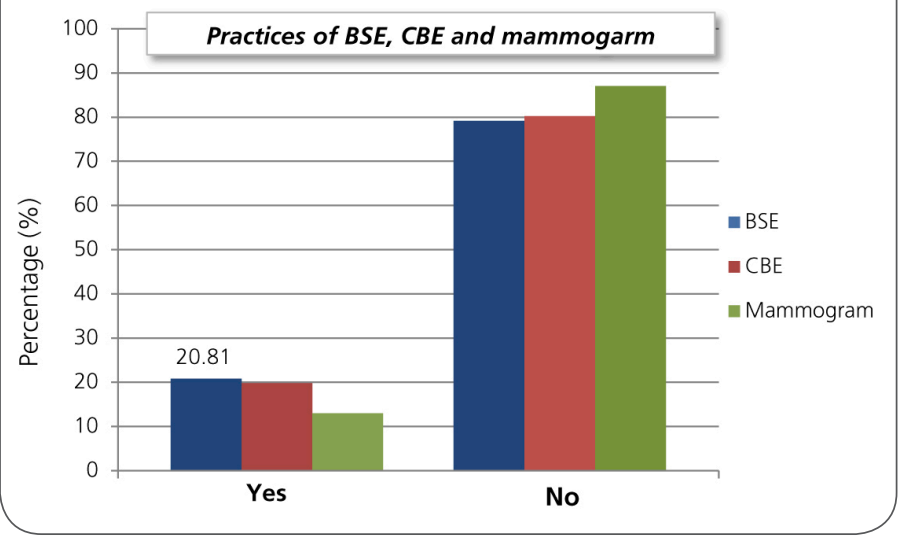

When asked about reasons for not going through mammogram screening tests if within the screening age, the highest percentage of chosen barrier hundred eighty nine (24.74\%) was "I don't have any problem and I think it is not important" followed by 180 (23.56\%) "Worry about the results", as illustrated in Figure 3. Assuming that their mammogram appointment was the following day, participants were asked to describe their feelings. Figure 4 summarized their answers. "Worried about the results" represented the highest percentage 348 (45.55\%) of feeling before the appointment. While the "lack of desire to go" forty nine $(6.41 \%)$ represents the least one.

As illustrated in Figure 5, out of 764 participants, only 159 (20.81\%), 151 (19.76\%) and ninety nine (12.96\%) practiced BSE, CBE and mammogram respectively. Consequently, BSE was the most method used for detection of breast cancer in comparison to $\mathrm{CBE}$ and mammography.

Tables $\mathbf{5 . 1}$ and $\mathbf{5 . 2}$ showed that the knowledge of BSE by women having bachelor was significantly more $436(57.1 \%)$ than the lower level of education 11 (1.5\%) (OR: 4 (1.4 - 11.1), $\mathrm{P}<0.031)$. On the other hand, the knowledge about CBE and mammograph was significantly decreased with increasing the age. However, women ranged from 41-50 years had less knowledge of CBE and mammograph by about more than twice in comparison to women aged from 20-30 years. (OR: 2.5 (1.1 5.7), $\mathrm{P}<0.046)$ and (OR: 2.4 (1.5 - 3.9), $\mathrm{P}<0.0002$ respectively). On comparing the married and single women, the married women showed significantly more knowledge of CBE and mammograph, about three times and twice respectively (OR: 2.9 (1.9 4.6), $\mathrm{P}<0.0001)$ and (OR: $1.6(1.2-2.1), P<0$, 003 respectively).

As illustrated in table $\mathbf{6 . 1}$ and $\mathbf{6 . 2}$, the practice of BSE was significantly decreased with increasing the age. And thus, women ranged from 51-60 years 15 (1.96\%) had less practice of BSE by about more than three times in comparison to younger ones 
Table 5.1. Knowledge of BSE, CBE and mammograph by various socio-demographic characteristics.

\begin{tabular}{|c|c|c|c|c|c|c|c|c|c|c|c|c|}
\hline \multirow{3}{*}{ Characteristics } & \multicolumn{4}{|c|}{ BSE } & \multicolumn{4}{|c|}{ CBE } & \multicolumn{4}{|c|}{ Mammograph } \\
\hline & \multicolumn{2}{|c|}{$\begin{array}{c}\text { Yes } \\
(n=657)\end{array}$} & \multicolumn{2}{|c|}{$\begin{array}{c}\text { No } \\
(n=107)\end{array}$} & \multicolumn{2}{|c|}{$\begin{array}{c}\text { Yes } \\
(n=666)\end{array}$} & \multicolumn{2}{|c|}{$\begin{array}{c}\text { No } \\
(n=98)\end{array}$} & \multicolumn{2}{|c|}{$\begin{array}{c}\text { Yes } \\
(n=476)\end{array}$} & \multicolumn{2}{|c|}{$\begin{array}{c}\text { No } \\
(n=288)\end{array}$} \\
\hline & $\mathrm{N}$ & $\%$ & $N$ & $\%$ & $\mathrm{~N}$ & $\%$ & N & $\%$ & N & $\%$ & N & $\%$ \\
\hline \multicolumn{13}{|l|}{ Age (years) } \\
\hline $20-30$ & 349 & 45.7 & 66 & 8.7 & 348 & 45.5 & 67 & 8.8 & 229 & 30 & 186 & 24.4 \\
\hline $31-40$ & 188 & 24.6 & 21 & 2.8 & 188 & 24.6 & 21 & 2.7 & 143 & 18.7 & 66 & 8.6 \\
\hline $41-50$ & 86 & 11.3 & 13 & 1.7 & 92 & 12 & 7 & 0.9 & 74 & 9.7 & 25 & 3.3 \\
\hline $51-60$ & 32 & 4.2 & 7 & 0.9 & 36 & 4.7 & 3 & 0.4 & 28 & 3.7 & 11 & 1.4 \\
\hline Above 60 & 2 & 0.3 & 0 & 0 & 2 & 0.3 & 0 & 0 & 2 & 0.3 & 0 & 0 \\
\hline$X^{2}$ ( $P$ value ) & \multicolumn{4}{|c|}{$4.852(0.303)$} & \multicolumn{4}{|c|}{$9.676(0.046)^{*}$} & \multicolumn{4}{|c|}{$21.528(0.0002)^{*}$} \\
\hline \multicolumn{13}{|l|}{ Education } \\
\hline Average & 11 & 1.5 & 6 & 0.8 & 12 & 1.6 & 5 & 0.7 & 11 & 1.5 & 6 & 0.7 \\
\hline Secondary & 101 & 13.2 & 23 & 3 & 105 & 13.7 & 19 & 2.4 & 72 & 9.4 & 52 & 6.9 \\
\hline Diploma & 71 & 9.3 & 10 & 1.3 & 75 & 9.8 & 6 & 0.8 & 54 & 7.1 & 27 & 3.5 \\
\hline Bachelor & 436 & 57.1 & 60 & 7.9 & 434 & 56.8 & 62 & 8.2 & 310 & 40.6 & 186 & 24.4 \\
\hline High education & 38 & 5.0 & 8 & 1 & 40 & 5.2 & 6 & 0.8 & 29 & 3.8 & 17 & 2.2 \\
\hline$X^{2}$ (P value) & \multicolumn{4}{|c|}{$10.645(0.031)^{*}$} & \multicolumn{4}{|c|}{$7.049(0.133)$} & \multicolumn{4}{|c|}{$1.666(0.797)$} \\
\hline \multicolumn{13}{|l|}{ Marital Status } \\
\hline Single & 271 & 35.5 & 54 & 7.1 & 261 & 34.2 & 64 & 8.4 & 183 & 24.0 & 142 & 18.6 \\
\hline Married & 386 & 50.5 & 53 & 6.9 & 405 & 53.0 & 34 & 4.4 & 293 & 38.4 & 146 & 19.1 \\
\hline$X^{2}$ ( $P$ value) & \multicolumn{4}{|c|}{$3.2(0.074)$} & \multicolumn{4}{|c|}{$23.839(0.0001)^{*}$} & \multicolumn{4}{|c|}{$8.658(0.003)^{*}$} \\
\hline
\end{tabular}

Table 5.2. Knowledge of BSE, CBE and mammograph by various socio-demographic characteristics.

\begin{tabular}{|c|c|c|c|}
\hline Characteristics & BSE & CBE & Mammograph \\
\hline \multicolumn{4}{|l|}{ Age (years) } \\
\hline $20-30^{R}$ & \multirow{5}{*}{ NS } & 1 & 1 \\
\hline $31-40$ & & $1.7(1-2.9)$ & $1.8(1.2-2.5)$ \\
\hline $41-50$ & & $2.5(1.1-5.7)$ & $2.4(1.5-3.9)$ \\
\hline $51-60$ & & $2.3(0.7-7.7)$ & $2.1(1-4.3)$ \\
\hline High education & & 40 & 29 \\
\hline \multicolumn{4}{|l|}{ Education } \\
\hline Average $^{R}$ & 1 & \multirow{5}{*}{ NS } & \multirow{5}{*}{ NS } \\
\hline Secondary & $2.4(0.8-7.1)$ & & \\
\hline Diploma & $3.9(1.2-12.8)$ & & \\
\hline Bachelor & $4(1.4-11.1)$ & & \\
\hline High education & $2.6(0.7-9.1)$ & & \\
\hline \multicolumn{4}{|l|}{ Marital Status } \\
\hline Single ${ }^{R}$ & \multirow{2}{*}{ NS } & 1 & 1 \\
\hline Married & & $2.9(1.9-4.6)$ & $1.6(1.2-2.1)$ \\
\hline
\end{tabular}




\section{INTERNATIONAL ARCHIVES OF MEDICINE

Table 6.1. Practice of BSE, CBE and mammograph by various socio-demographic characteristics.

\begin{tabular}{|c|c|c|c|c|c|c|c|c|c|c|c|c|}
\hline \multirow{3}{*}{ Characteristics } & \multicolumn{4}{|c|}{ BSE } & \multicolumn{4}{|c|}{ CBE } & \multicolumn{4}{|c|}{ Mammograph } \\
\hline & \multicolumn{2}{|c|}{$\begin{array}{c}\text { Yes } \\
(n=159)\end{array}$} & \multicolumn{2}{|c|}{$\begin{array}{c}\text { No } \\
(n=605)\end{array}$} & \multicolumn{2}{|c|}{$\begin{array}{c}\text { Yes } \\
(n=151)\end{array}$} & \multicolumn{2}{|c|}{$\begin{array}{c}\text { No } \\
(n=613)\end{array}$} & \multicolumn{2}{|c|}{$\begin{array}{c}\text { Yes } \\
(n=99)\end{array}$} & \multicolumn{2}{|c|}{$\begin{array}{c}\text { No } \\
(n=665)\end{array}$} \\
\hline & N & $\%$ & $\mathrm{~N}$ & $\%$ & $\mathrm{~N}$ & $\%$ & $\mathrm{~N}$ & $\%$ & $\mathrm{~N}$ & $\%$ & $\mathrm{~N}$ & $\%$ \\
\hline \multicolumn{13}{|l|}{ Age (years) } \\
\hline $20-30$ & 67 & 8.76 & 348 & 45.5 & 32 & 4.18 & 383 & 50.1 & 16 & 2.09 & 399 & 52.2 \\
\hline $31-40$ & 46 & 6.02 & 163 & 21.3 & 58 & 7.59 & 151 & 19.8 & 27 & 3.53 & 182 & 23.8 \\
\hline $41-50$ & 30 & 3.92 & 69 & 9 & 42 & 5.49 & 57 & 7.4 & 38 & 4.97 & 61 & 8 \\
\hline $51-60$ & 15 & 1.96 & 24 & 3.2 & 17 & 2.22 & 22 & 2.9 & 17 & 2.22 & 22 & 2.9 \\
\hline Above 60 & 1 & 0.13 & 1 & 0.1 & 2 & 0.26 & 0 & 0 & 1 & 0.13 & 1 & 0.1 \\
\hline$X^{2}$ ( $P$ value ) & \multicolumn{4}{|c|}{$19.484(0.0006)^{*}$} & \multicolumn{4}{|c|}{$100.563(0.0001)^{*}$} & \multicolumn{4}{|c|}{$122.108(0.0001)^{*}$} \\
\hline \multicolumn{13}{|l|}{ Education } \\
\hline Average & 2 & 0.26 & 15 & 2 & 3 & 0.39 & 14 & 1.8 & 3 & 0.39 & 14 & 1.8 \\
\hline Secondary & 28 & 3.66 & 96 & 12.6 & 21 & 2.74 & 103 & 13.5 & 19 & 2.48 & 105 & 13.7 \\
\hline Diploma & 21 & 2.74 & 60 & 7.8 & 23 & 3.01 & 58 & 7.6 & 15 & 1.96 & 66 & 8.7 \\
\hline Bachelor & 100 & 13.08 & 396 & 51.8 & 97 & 12.69 & 399 & 52.3 & 60 & 7.85 & 436 & 57.1 \\
\hline High education & 8 & 1.04 & 38 & 5 & 7 & 0.91 & 39 & 5 & 2 & 0.26 & 44 & 5.8 \\
\hline$X^{2}$ ( $P$ value ) & \multicolumn{4}{|c|}{$2.819(0.589)$} & \multicolumn{4}{|c|}{$5.092(0.278)$} & \multicolumn{4}{|c|}{$6.516(0.164)$} \\
\hline \multicolumn{13}{|l|}{ Marital Status } \\
\hline Single & 54 & 7.06 & 271 & 35.5 & 30 & 3.92 & 295 & 38.7 & 17 & 2.22 & 308 & 40.3 \\
\hline Married & 105 & 13.74 & 334 & 43.7 & 121 & 15.83 & 318 & 41.6 & 82 & 10.73 & 357 & 46.7 \\
\hline$X^{2}$ ( P value ) & \multicolumn{4}{|c|}{$6.043(0.014)^{*}$} & \multicolumn{4}{|c|}{$39.575(0.0001)^{*}$} & \multicolumn{4}{|c|}{$29.944(0.0001)^{*}$} \\
\hline
\end{tabular}

Table 6.2. Practice of BSE, CBE and mammography by various socio-demographic characteristics.

\begin{tabular}{|c|c|c|c|}
\hline Characteristics & BSE & CBE & Mammograph \\
\hline \multicolumn{4}{|l|}{ Age (years) } \\
\hline $20-30^{R}$ & 1 & 1 & 1 \\
\hline $31-40$ & $1.5(1-2.2)$ & $4.6(2.9-7.4)$ & $3.7(1.9-7)$ \\
\hline $41-50$ & $2.3(1.4-3.7)$ & $8.8(5.2-15.1)$ & $15.5(8.2-29.6)$ \\
\hline $51-60$ & $3.2(1.6-6.5)$ & $9.2(4.5-19.2)$ & $19.3(8.6-43.2)$ \\
\hline \multicolumn{4}{|l|}{ Education } \\
\hline \multicolumn{4}{|l|}{ Average $R$} \\
\hline Secondary & \multirow{3}{*}{ NS } & \multirow{3}{*}{ NS } & \multirow{3}{*}{ NS } \\
\hline Diploma & & & \\
\hline Bachelor & & & \\
\hline \multicolumn{4}{|l|}{ Marital Status } \\
\hline Single ${ }^{R}$ & 1 & 1 & 1 \\
\hline Married & $1.6(1.1-2.3)$ & $3.7(2.4-5.8)$ & $4.2(2.4-7.2)$ \\
\hline
\end{tabular}

R: Reference category, OR: Odds ratio, Cl: Confidence intervals, NS: Non significant result 
67 (8.76\%) (OR: 3.2 (1.6-6.5), $\mathrm{P}<0.0006)$. Concerning the practice of CBE and mammograph, it was found that the women aged from 41-50 years were significantly practiced CBE and mammograph more than $20-30$ aged ones $(P<0.0001)$. On the other hand, the married women showed significantly more practice of BSE, CBE and mammograph than single ones by about twice, more than three and four times respectively (OR : 1.6 (1.1-2.3), $P<0.014$; OR :3.7 (2.4-5.8), $P<0.0001$ and $O R$ : 4.2 (2.4-7.2), $\mathrm{P}<0.0001$ respectively).

\section{Discussion}

In Saudi Arabia, social and demographic factors have influenced the late presentation of the disease [15]. The average age at the presentation of breast cancer in Arab countries appears to be a decade earlier than in Western countries. If this is true, this has important implications for screening and cancer management strategies in these countries, including the ideal age at which to begin screening. Adoption of Western guidelines "without critical amendment" in planning breast cancer programs will waste the resources without achieving desired outcomes. Determination of the true frequency and age of onset of breast cancer in Arab women should be an important research priority [16].

Three hundred and seventy six female teachers from 20 schools in the central region of Saudi Arabia were surveyed. Ninety percent of them were found to have poor knowledge and wrong beliefs. The subjects had the same level of education, income, background and all lived in the same city [17]. The study reported that only $9.3 \%$ of teachers identified mammography as a screening method. Another study that took place in the same region included 149 nursing students from two colleges, showed that $66 \%$ practiced BSE on regular basis and confirmed a positive relationship between perception and years of experience [18]. Due to their specialty, $44 \%$ of the participants learned about BSE from their college curriculum. As evident from the existing literatures, studies on breast cancer screening and mammography in Saudi Arabia, have so far been done within a controlled population (i.e. at universities, colleges or schools within one region), which resulted in no variation in age, education level, occupation, region of residence of the participants.

Ideally, awareness and educational campaigns should target population of all ages to reinforce the importance of early screening. The present study has managed to research electronically diverse women in the western, eastern, central, southern and northern regions of the country [14]. The present study included women in all regions of Saudi Arabia and evaluated their awareness about breast cancer, risk factors, signs, symptoms, BSE, CBE and mammography. Also, the present work evaluated BSE, CBE and mammography attitude and screening practice.

In the present study, $92.54 \%$ of the studied population knew that a breast lump could be a warning sign of breast cancer. In another study among a Nigerian population, only $33 \%$ of population identified that a breast mass is the commonest symptom of breast cancer [19]. In the present work, 75.79\% participants answered correctly when they asked about bloody discharge from nipple and 83.64\% about change in breast skin. Whereas in the study carried out by Haji-Mahmoodi et al., (2002) [20], only $27 \%$ knew that pain is not a cardinal feature of breast cancer. Other studies have also reported similar findings [21, 22]. These wrong informations or assumptions about breast lumps may account for some of the reasons why some of our patients present late to hospital $[21,23]$. In the study on why patients with breast cancer present late for management, several studies found that majority of the patients has a wrong perception of malignant diseases of the breast, particularly the early symptoms of breast cancer [24, 25]. 
Regarding to associated risk factors for breast cancer, about $69.11 \%$ and $64.53 \%$ knew that smoking and a positive family history of breast cancer respectively are risk factors, while 43.59\% knew that obesity also an implicated risk factor. Most of the participants in this study didn't know the association between breast cancer and short periods of breast feeding (1.83\%), early menarche $(11.13 \%)$ and late menopause (28.14\%). Also, around $46.60 \%, 52.36 \%$ and $24.48 \%$ of participants realized the effect of use of contraceptive, advanced age and delivery of first child after the age 30 respectively as risk factors of breast cancer. Participants showed poor understanding of major breast cancer risk factors. The perception of the use of contraceptive by $46.6 \%$ might reflect the religious culture that encourages natural methods of birth control [26, 27].

These result were near to that reported in study done by Adebamowo and Ajayi, (2000) [21]; Odusanya, (2001) [28]; Adebamowo and Adekunle, (1999) [29], where these studies have shown that the incidence of breast cancer is said to be slightly higher in persons that have first degree relatives with a history of breast cancer, persons that have early menarche and late menopause and those that use oral contraceptives, persons do not breast feed and those women having their first birth after age 35 or nulliparous women. The incidence is also increased with increasing age of the patient, smoking, obesity, physical inactivity, radiation exposure, intake of alcohol and high fat. Thus further health education on associated risk factors and protective factors is desirable. This may influence the attitudes, practices and lifestyle of our patient positively. In a study done by Adebamowo and Adekunle, (1999) [30], it was observed that patients with positive family history tend to present early for management.

Also, one of the major factor, why we experience late presentation of breast cancer, is that most women do not carry out BSE and CBE they do not also take advantage of the screening role of mam- mography. It is either that they have never heard of breast self-examination or they do not know how to carry it out $[30,31]$.

Several recent studies that examined the knowledge and attitudes toward breast cancer and breast self-examination found that with increasing age, women doubted the benefits of early screening for breast carcinomas. It was shown that awareness about breast cancer screening was higher among younger women compared to older women over 50 years [15].

The conservative nature of our society still prevents women from directly discussing sensitive issues with their healthcare providers; therefore, there is a vital need to educate female members of the society to overcome knowledge deficits. Other factors like embarrassment and fear of social implications arising from Saudi Arabia culture and absence of a national screening program are not making things any better [14].

Ever since food and drug administration (FDA) approved the use of tools for breast cancer screening, mammography has helped reducing mortality rate in USA by $35 \%$ in women aged between 50 and 69 [32]. In fact, the American Cancer Society has made it mandatory that all women over 40 be screened by mammograms. However, there are no structured national breast cancer screening programs in most of the Arab world. Specifically in Saudi Arabia, fear and misconceptions about mammograms have delayed early treatment and decreased the survival rate [33].

The importance of BSE, CBE and mammography for early detection of breast cancer was identified by 657 (85.99\%), 666 (87.17\%) and 476 (62.3\%) respectively by the study population. However, only $37.57 \%$ identified the appropriate time for BSE. Also, only 33.64\% identified the correct age for mammograph screening. The age and marital status were variable found to have a significant correlation $(P<0.05)$ with knowledge of $C B E$ and mammography. On the other hand, the perception 
of BSE was significantly associated $(P<0.031)$ with the education level.

Only 159 (20.81\%), 151 (19.76\%) and 99 (12.96\%) of the participants practiced BSE, CBE and mammograph respectively. This was affected by variables like age and marital status $(P<0.05)$. The present results revealed that the worry about finding a lump was the most obvious reason could sing negative attitude of around 31.94\% and 45.55\% of women toward breast cancer screening by $\mathrm{CBE}$ and mammograph respectively.

Several studies on BSE have reported similar findings $[31,34]$. This may be as a result of poor health education in our society. In a study done among secondary school teachers, only about $25 \%$ had adequate knowledge of breast self- examination [28]. The implication therefore is that $75 \%$ of such a group of teachers cannot impact on their students the importance of BSE. Ferlay et al., (2013) [35], also emphasized the need for adolescents to be properly taught the routine of BSE as this will greatly influence their practice as they grow older. $A$ related study showed that some nurses do not appreciate the importance of BSE and the need for CBE [28]. The implication of all of these is that there is the need for proper orientation about breast cancer among the various caregivers which in turn is expected to boost the level of awareness in the society.

Regarding to mammograph, the study results were consistent with that reported by Okobia et al., (2006) [36]. Health education about the benefits of mammography screening should be encouraged. Association of breast cancer knowledge with age, marriage and education level variables has been identified in other studies. Data from the National American Survey on cancer risk revealed poor knowledge among the least educated women [37].

Similar findings were reported among Hispanic women (38). The 64.53\%Women's limited knowledge about breast cancer had been identi- fied elsewhere in developed and under developing countries [31, 37, 39].

\section{Conclusion}

This study demonstrates that breast cancer awareness activities and campaigns are limited in the country, therefore efforts are still needed. Adequate health education programs should be planned throughout the year and should be widely spread. The study points to the insufficient knowledge of female about breast cancer and identifies the negative influence of low knowledge on the attitude and practice of BSE, CBE and mammography. Accordingly, relevant educational programs, based on a national base, to improve the knowledge level of women regarding breast cancer are needed. There is very urgent need for regular update courses for health workers concerning breast cancer education including screening methods. 


\section{References}

1. Bray F, Ren JS, Masuyer E, Ferlay J. Global estimates of cancer prevalence for 27 sites in the adult population. Int J. Cancer. 2013; 132: 1133-1145.

2. Soerjomataram I, Lortet TJ, Parkin DM, Ferlay J, Mathers C, Forman D, Bray F. Global burden of cancer; a systematic analysis of disability-adjusted life-years in 12 world regions. J. Lancet. 2012; 380: 1840-1850.

3. Stojadinovic A, Summers TA, Eberhardt J, Cerussi A, Grundfest W, Peterson CM, Brazaitis $M$, Krupinski $E$, Freeman $H$. Consensus recommendations for advancing breast cancer: risk identification and screening in ethnically diverse younger women. J. Cancer. 2011; 2: 210-227.

4. American Cancer Society. Cancer facts \&figures, USA. 2012.

5. National Comprehensive Cancer Network. Clinical practice guidelines in oncology. 2013.

6. National Cancer Institute. PDQ breast cancer treatment, USA. 2013.

7. Dundar PE, Ozmen D, Ozturk B, Haspolat G, Akyildiz F, Coban $\mathrm{S}$. The knowledge and attitudes of breast self-examination and mammography in a group of women in a rural area in western Turkey. BMC cancer. 2006; 24: 6-43.

8. Lee EO, Ahn SH, You C, Lee DS, Han W, Choe KJ. Determining the main risk factors and high-risk groups of breast cancer using a predictive model for breast cancer risk assessment in South Korea. Cancer Nurs. 2004; 27: 400-406.

9. Baig M, Subramaniam V, Chandrasegar A, Khan T. A population based survey on knowledge and awareness of breast cancer in the suburban females of Sungai Petani. IJCRIMPH. 2011; 3: 670-709

10. Hackshaw AK, Paulo EA. Breast self-examination and death from breast cancer meta-analysis. Br. J. Cancer. 2003; 88: 1047-1053.

11. Benjamin O, Anderson BS, Lim S, Robert AS, Taplin S. Early detection of breast cancer in countries with limited resources. Breast J. 2003; 9: S51-S59.

12. Sohel MM. Knowledge, attitude and practice regarding breast cancer among medical students of Bangladesh; a protocol study. Master thesis in Public health. Department of Epidemiology, Public Health and Clinical Medicine, UmeåUniversity, Umeå. 2007.

13. Ameer K, Abdulie SM, Pal SK, Arebo K, Kassa, GG. Breast cancer awareness and practice of breast self-examination among female medical students in Haramaya University, Harar, Ethiopia. IJIMS. 2014; 2: 109-119.

14. Hagi SK, Khafaji MA. Do Women in Saudi Arabia "Think Pink"? AJRC. 2013; 7: 43-58.
15. Abdel Hadi M. Breast cancer awareness campaign: will it make a difference? J Fam Community Med. 2006; 13: 115-118.

16. Najjar H, Easson A. Age at diagnosis of breast cancer in Arab nations. Int J Surg. 2010; 8: 448-452.

17. Dandash K, Al-Mohaimeed A. Knowledge, attitudes and practices surrounding breast cancer and screening in female teachers of Buraidah, Saudi Arabia. Int J Health Sci. 2007; 1: 61-71.

18. Alsaif A. Breast self-examination among Saudi female nursing students in Saudi Arabia. Saudi Med J. 2004; 25: 1574-1578.

19. Uche EE. Cancer awareness among a Nigeria population. Trop. Doct. 1999; 29: 39-40.

20. Haji-Mahmoodi M, Montazeri A, Jarvandi S, Ebrahim M, Haghighat S, Harirchi I. Breast self-examination: knowledge, attitudes and practices among female health care workers in Tehran. Iran. Breast J. 2002; 8: 222-305.

21. Adebamowo CA, Ajayi OO. Breast cancer in Nigeria. West Afr J Med. 2000; 19: 179-191.

22. Visvanathan R. Breast cancer in Nigeria women. Br J Surg. 1993; 80: 126-209.

23. Katz RC, Meyers K, Walls J. Cancer awareness and selfexamination practices in young man and women. J Behar Med. 1995; 18: 377-384.

24. Ikpatt, O.F.; Kuopoo, I.; Ndoma-Egbe, R. and Collen, Y. (2002): Breast cancer in Nigeria and Finland: epidemiological, clinical and histological comparison. Anticancer Res; 22: 3005-4012.

25. Salleh MR. The consultation of traditional healers by Malay patients. Med J Malaysia. 1989; 44: 3-13.

26. Maxwell AE, Bastani R, Warda US. Misconceptions and mammography use among Filipino-and Korean-American women. Ethic Dis J. 1998; 8:377-384.

27. Paul C, Barratt A, Redman S, Cockburn J, Lowe J. Knowledge and perceptions about breast cancer incidence, fatality and risk among Australian women. Aust N Z J Public Health. 1999; 23: 396-400.

28. Odusanya OO. Breast cancer: knowledge, attitudes and practices of female school teachers in Lagos. Nigeria Breast J. 2001; 7: 171-205.

29. Adebamowo CA, Adekunle OO. Case controlled study of the epidemiological risk factors of breast cancer in Nigeria. $\mathrm{Br} \mathrm{J}$ Surg. 1997; 86: 665-708.

30. Adderly-Kelly B, Green PM. Breast cancer education, selfefficacy and screening in older African American women. J Natl Black Nurses Assoc. 1997; 9: 45-57. 
31. Abdel-Fattah M, Zaki A, Bassili A, Shazly, Tognoni G. Breast self-examination practice and its impact on breast cancer diagnosis in Alexandria, Egypt. East Mediterr Health J. 2000; 6: 34-40.

32. Baxi S, Snow J, Liberman L, Elkin E. The future of mammography: radiology residents' experiences, attitudes, and opinions. Am. J. of Roentgen. 2010; 194: 1680-1686.

33. Alam A. Knowledge of breast cancer and its risk and protective factors among women in Riyadh. Ann Saudi Med. 2007; 26: 272-307.

34. Hall LS. Breast self-examination: use of a visual reminder to increase practice. AAOHN J. 1992; 40: 186-192.

35. Ferlay J, Steliarova-Foucher E, Lortet-Tieulent J, Rosso S, Coebergh J, Comber H, et al. Cancer incidence and mortality patterns in Europe: Estimates for 40 countries in 2012. EJC. 2013; 49: 1374-1403.

36. Okobia MN, Bunker $\mathrm{CH}$, Okonofua F, Osime U. Knowledge, attitude and practice of Nigerian women towards breast cancer: a cross-sectional study. World J Surg Oncol. 2006; 4: 6-11.

37. Breslow RA, Sorkin JD, Frey CM, Kessler LG. Americans' knowledge of cancer risk and survival. Prev Med. 1997; 26: 170-207.

38. Ramirez AG, Suarez L, Laufman L, Barroso C, Chalela P. Hispanic women's breast and cervical cancer knowledge, attitudes and screening behaviors. Am J Health Promot. 2000; 14: 292-300.

39. Leslie NS, Deiriggi P, Gross S, DuRant E, Smith C, Veshnesky JG. Knowledge, attitudes, and practices surrounding breast cancer screening in educated Appalachian women. Oncol Nurs Forum. 2003; 30: 659-667.

\section{Comment on this article:}

\section{Qf $B$ in $8+\mathbf{S} P$}

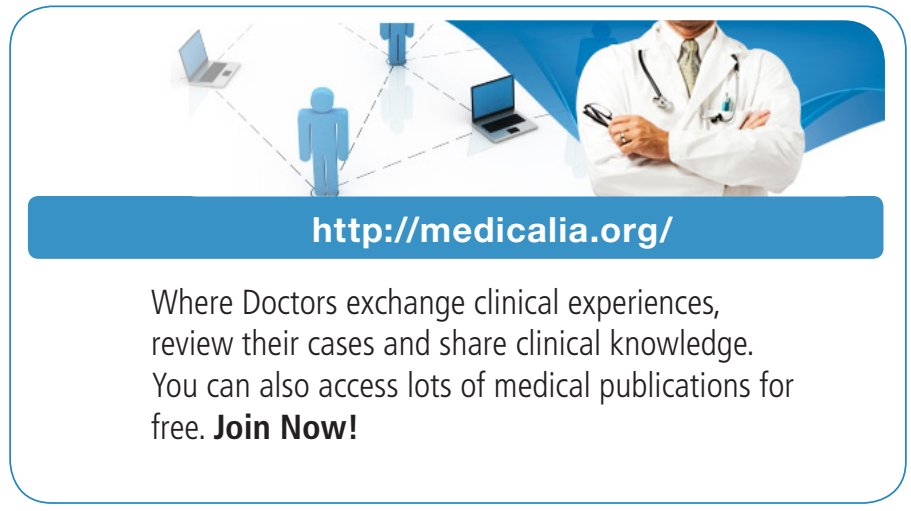

\section{Publish with iMedPub}

\section{http://www.imed.pub}

International Archives of Medicine is an open access journal publishing articles encompassing all aspects of medical science and clinical practice. IAM is considered a megajournal with independent sections on all areas of medicine. IAM is a really international journal with authors and board members from all around the world. The journal is widely indexed and classified Q1 in category Medicine. 